\title{
Osteoinductive Material to Fine-Tune Paracrine Crosstalk of Mesenchymal Stem Cells With Endothelial Cells and Osteoblasts
}

\author{
Hassan Rammal ${ }^{1,2}$, Laura Entz ${ }^{1}$, Marie Dubus ${ }^{1,2}$, Aurélie Moniot ${ }^{1}$, Nicolae B. Bercu ${ }^{3}$, \\ Johan Sergheraert 1,2,4, Sophie C. Gangloff ${ }^{1,5}$, Cédric Mauprivez ${ }^{1,2,4}$ and \\ Halima Kerdjoudj ${ }^{1,2 \star}$ \\ ${ }^{1}$ EA 4691, Biomatériaux et Inflammation en Site Osseux (BIOS), SFR CAP Santé (FED4231), Université de Reims \\ Champagne Ardenne, Reims, France, ${ }^{2}$ UFR d'Odontologie, Université de Reims Champagne Ardenne, Reims, France, \\ ${ }^{3}$ EA 4682, Laboratoire de Recherche en Nanoscience (LRN), Université de Reims Champagne-Ardenne, Reims, France, \\ ${ }^{4}$ Pôle Médecine bucco-dentaire, Hôpital Maison Blanche, Centre Hospitalier Universitaire de Reims, Reims, France, \\ ${ }^{5}$ UFR de Pharmacie, Université de Reims Champagne Ardenne, Reims, France
}

OPEN ACCESS

Edited by:

Maria Chatzinikolaidou, University of Crete, Greece

Reviewed by:

Roberta Tasso,

University of Genoa, Italy

Anna Lange-Consiglio,

University of Milan, Italy

*Correspondence:

Halima Kerdjoud

halima.kerdjoudj@univ-reims.fr

Specialty section:

This article was submitted to Tissue Engineering and Regenerative

Medicine,

a section of the journal Frontiers in Bioengineering and

Biotechnology

Received: 01 July 2019 Accepted: 23 September 2019 Published: 09 October 2019

Citation:

Rammal H, Entz L, Dubus M, Moniot A, Bercu NB, Sergheraert J,

Gangloff SC, Mauprivez $C$ and Kerdjoudj H (2019) Osteoinductive Material to Fine-Tune Paracrine Crosstalk of Mesenchymal Stem Cells

With Endothelial Cells and

Osteoblasts.

Front. Bioeng. Biotechnol. 7:256.

doi: 10.3389/fbioe.2019.00256
While stem cell/biomaterial studies provide solid evidences that biomaterial intrinsic cues deeply affect cell fate, current strategies tend to neglect their effects on mesenchymal stem cells (MSCs) secretory activities and resulting cell-crosstalks. The present study aims to investigate the impact of bone-mimetic material (B-MM), with intrinsic osteoinductive property, on MSCs mediator secretions; and to explore underlying effects on cells involved in bone regeneration. Human MSCs were cultured, on B-MM, made from inorganic calcium phosphate supplemented with chitosan and hyaluronic acid biopolymers. Collected MSCs culture media were assessed for mediators release quantification and used further to stimulate endothelial cells (ECs) and alveolar bone derived osteoblasts (OBs). Without osteogenic supplements, MSCs committed into bone lineage forming thus 3D bone-like nodules after 21 days. Despite a weak percentage of cell commitment, our data elucidate new aspects of osteoinductive material effect on MSCs functions through the regulation of the secretion of mediators involved in bone regeneration and subsequently the MSCs/ECs indirect crosstalk with osteogenesis-boosting effect. Using MSCs culture media, we demonstrate a large potential of osteoinductive materials and MSCs in bone regenerative medicine. Such strategies could help to address some insights in cell-free therapies using MSCs derived media.

Keywords: mesenchymal stem cells, paracrine activities, cell crosstalk, osteoinductive material, culture media

\section{INTRODUCTION}

During the last decade, mesenchymal stem cells (MSCs) have been proven effective for bone regeneration as evidenced through in vitro, in vivo animal experiments and clinical trials (Asatrian et al., 2015; Jin and Lee, 2018). Scientific investigations have tried to understand the MSCs biological mechanism of action in skeletal tissue repair and to decipher their potential in cell therapy and regenerative medicine. Early MSCs studies in bone regenerative medicine were focused on their great potential to differentiate into multiple tissue types and supported the idea that MSCs have the 


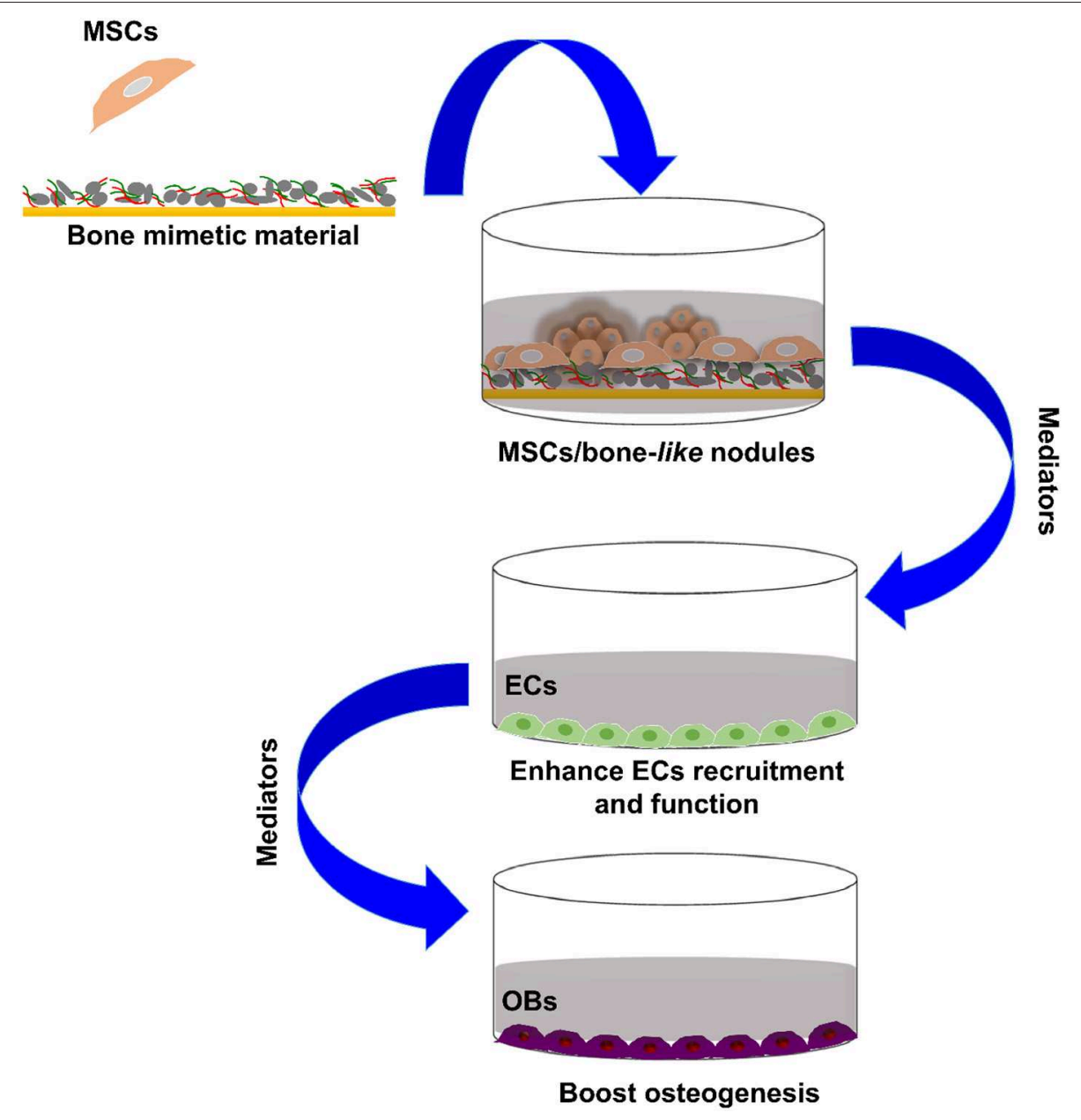

GRAPHICAL ABSTRACT | Bone forming cells paracrine crosstalk.

capacity for tri-lineage differentiation into, osteoblasts (OBs), chondrocytes or adipocytes. Such optimism suggested that upon implanting, MSCs would colonize and differentiate at the bone lesion site along the osteoblastic lineage and thus replace damaged resident OBs (Bruder et al., 1994, 1998; Golchin and Farahany, 2019).

Bone tissue engineering has emerged as an interdisciplinary strategy combining biomaterials, MSCs and/or biologically active molecules, aiming to reconstruct injured or lost bone (Place et al., 2009). Along with the direct relationship between osteoblastic lineage and bone formation, major developments were focused on osteoinductive materials able to induce MSCs osteoblastic differentiation, without chemical exogenous stimuli. Materials mimicking physicochemical and mechanical properties of bone extracellular matrix are developed to guide MSCs fate (Gao et al., 2017; Li et al., 2017; Zhang et al., 2018a). Indeed, MSCs sense physical and mechanical signals from their microenvironment and simultaneously convert them into environmental signals that regulate their behavior. We have recently developed a versatile osteoinductive coating made of organic chitosan/hyaluronic acid biopolymers and inorganic calcium phosphate, with a compositional analogy to human mineral bone and offers interesting properties for bone regenerative medicine, as it provides a suitable framework for MSCs osteogenic commitment (Rammal et al., 2017a).

MSCs are a heterogeneous population that contains a very low yield of cells able to differentiate into osteoblastic lineage. Once injected into a damaged tissue, MSCs showed a relatively poor rate of cell engraftment and engrafted ones are rather to be short-lived (Wang et al., 2014). Taken together, the current research seems to argue that MSCs differentiation contributes minimally to tissue regeneration while paracrine activities play a more predominant role. MSCs secrete cytokines, chemokines and growth factors to orchestrate tissue repair (i.e., by promoting angiogenesis and tissue regeneration and inhibiting fibrosis, apoptosis and inflammation) (Glenn and Whartenby, 2014; Wang et al., 2014; Haumer et al., 2018; Najar et al., 2018). Furthermore, an increase in bone resistance to fracture along with an increase in bone mineral density were reported following MSCs-based therapy for osteoporosis (Aghebati-Maleki et al., 
Indirect crosstalk between MSCs and endothelial cells (ECs)

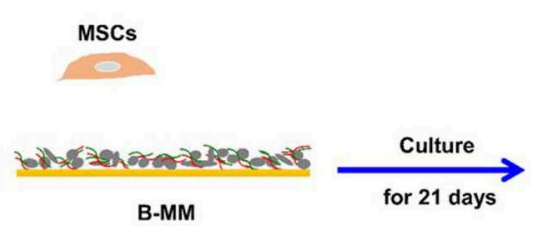

B-MM

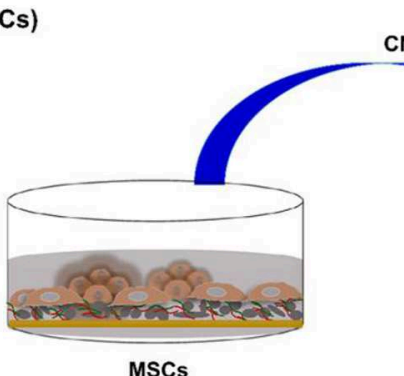

MSCs

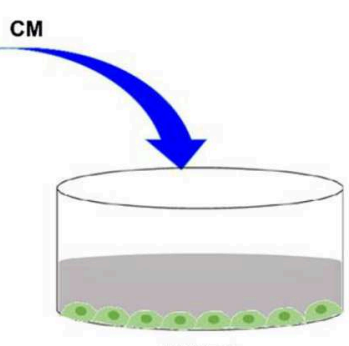

HUVECS

Indirect crosstalk between MSCs and osteoblast (OBs)
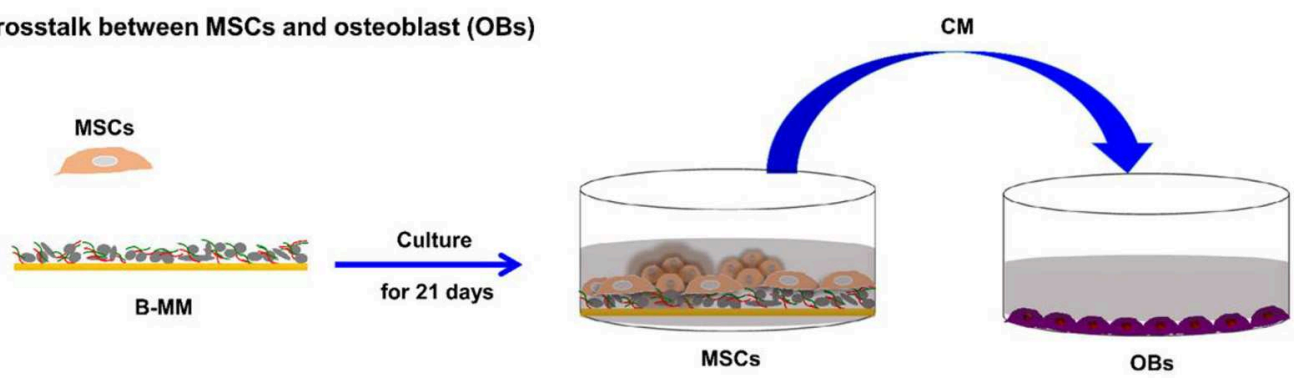

Indirect crosstalk between MSCs, EC and OBs

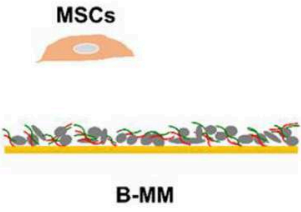

B-MM

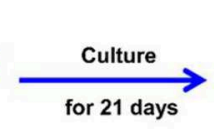

for 21 days

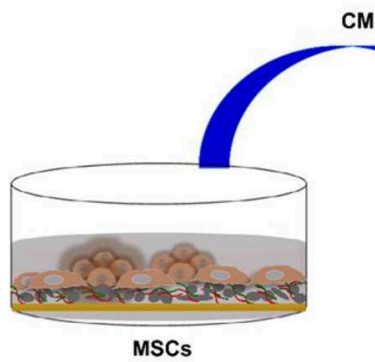

MSCs

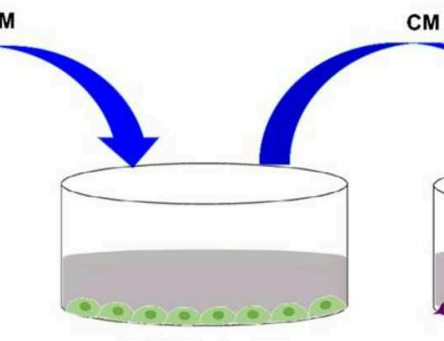

HUVECs for $48 \mathrm{~h}$

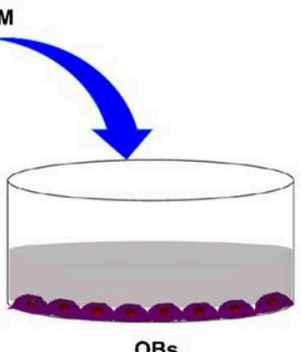

OBs

FIGURE 1 | Representative schema of the study experimental design.

2018; Saito et al., 2018). Local administrations of allogenic MSCs into the bone marrow cavity of irradiation-induced osteoporotic mice or of ovariectomy-induced osteoporotic rats were found to be effective against osteoporosis progression, to enhance bone apposition, and to promote freshly osteoid formation. Using MSCs to treat osteoporosis is already in clinical trials and no outcomes have been described (ClinicalTrials.gov identifier: NCT02566655; NCT01532076).

In light of these data, the present study investigates the capacity of bone-mimetic material (B-MM) to promote proregenerative secretome from MSCs especially on the production of either angiogenic or osteogenic factors (Figure 1). Our results provide, herein, evidences that the indirect crosstalk between MSCs and various cell types involved in bone regeneration, namely endothelial cells (ECs) and OBs, might be finely regulated by B-MM.

\section{MATERIALS AND METHODS}

\section{Experimental Design}

To investigate the effect of bone-mimetic material (B-MM) on MSCs differentiation and secretome, Wharton's jelly derived
MSCs were cultured for 21 days on both B-MM and glass. The study of the crosstalk between MSCs and EC or OBs was performed using MSCs culture media collected between 19th and 21st day of culture (Figure 1).

\section{Bone-Mimetic Material}

\section{Material}

Calcium chloride hydrate $\left(\mathrm{CaCl}_{2}, 2 \mathrm{H}_{2} 0: 0.32 \mathrm{M}\right)$ and chitosan (low molecular weight: $0.3 \mathrm{mg} / \mathrm{mL}$ ) were dissolved in $\mathrm{NaCl}$ $(0.15 \mathrm{M}) / \mathrm{HCl}(2 \mathrm{mM})$ buffer $\mathrm{pH} 4$ (A solution). Sodium dihydrogen phosphate hydrate $\left(\mathrm{NaH}_{2} \mathrm{PO}_{4}: 0.19 \mathrm{M}\right)$ and hyaluronic acid (molecular weight of $200 \mathrm{kDa}: 0.3 \mathrm{mg} / \mathrm{mL}$ ) were prepared in $\mathrm{NaCl}(0.15 \mathrm{M})$ buffer $\mathrm{pH} 10$ (B solution). Both salt solutions were prepared in ultrapure water (Millipore ${ }^{\circledR}$ ). Coverslips of $14 \mathrm{~mm}$ diameter were provided from Thermo Scientific. Each experiment was preceded by a cleaning step of the glass coverslips with sodium dodecyl sulfate $(100 \mathrm{mM})$ for $15 \mathrm{~min}$ at $100^{\circ} \mathrm{C}$. After an intensive ultrapure water (Millipore ${ }^{\circledR}$ ) rinse, coverslips were brought in contact with $\mathrm{HCl}(100 \mathrm{mM})$ for $15 \mathrm{~min}$ at $100^{\circ} \mathrm{C}$ and finally rinsed with ultrapure water and kept at $4^{\circ} \mathrm{C}$. 


\section{Substrate Build-Up}

An automated spraying device was used for bone-mimetic material (B-MM) build-up. This device is constituted of four identical Airbrushes VL (Paasche ${ }^{\circledR}$, USA) nozzles. Each nozzle is pressurized by in-house compressed air line under a pressure of 1 bar and connected to solenoid valves. The spraying of the different solutions, following a chosen deposition sequence, is obtained by a succession of closings and openings of the valves controlled by homemade software. Three nozzles allow spraying of the A solution, the B solution and of the rinsing solution. The fourth nozzle, free of solution, is used for the drying step. The cleaned coverslip is mounted vertically on a mobile holder. For homogenous B-MM build-up, the holder was rotated at 150 rpm. Both A and B solutions were sprayed simultaneously, on coverslip, for $2 \mathrm{~s}$ followed by a rinsing step of $2 \mathrm{~s}$ with ultrapure water and a drying step of $2 \mathrm{~s}$ under compressed air. These steps were repeated 50 times and polymer concentrations were adjusted after calculation of flows during spraying in order to keep a charge ratio hyaluronic acid/chitosan constant and equal to 0.7 to optimize the complex formation (Cado et al., 2012).

\section{Cell Culture}

Human specimen (umbilical cord, mandibular bone specimen, and venous blood) harvestings were approved ethically and methodologically by our local Research Institution and were conducted with informed patients (written consent) in accordance with the usual ethical legal regulations (Article $\mathrm{R}$ 1243-57). All procedures were done in accordance with our authorization and registration number DC-2014-2262 given by the National "Cellule de Bioéthique."

\section{Wharton's Jelly Mesenchymal Stem Cells (MSCs)}

MSCs were enzymatically isolated from fresh human umbilical cords obtained after full-term births (Mechiche Alami et al., 2014). MSCs were amplified at a density of 3 $\times 10^{3} \mathrm{cell} / \mathrm{cm}^{2}$ in $\alpha$-MEM culture medium supplemented with 10\% decomplemented fetal bovine serum (FBS), 1\% Penicillin/Streptomycin/Amphotericin B and 1\% Glutamax ${ }^{\circledR}$ $(v / v$, Gibco $)$ and maintained in a humidified atmosphere of $5 \%$ $\mathrm{CO}_{2}$ at $37^{\circ} \mathrm{C}$ with a medium change every 2 days. At the fourth passage, MSCs were seeded in 24 well plates at $24 \times 10^{3} \mathrm{cells} / \mathrm{cm}^{2}$ on UV-decontaminated B-MM or UV-decontaminated glass coverslip. MSCs were cultured for 21 days with a culture medium change every 2 days. Between 19th and 21st day of culture, MSCs culture media (MSCs-CM) were collected, centrifuged at $300 \mathrm{~g}$ and stored at $-80^{\circ} \mathrm{C}$. For a better comprehension, culture media from MSCs cultured on B-MM and glass were designated as $\mathrm{CM}_{\mathrm{B}-\mathrm{MM}}$ and $\mathrm{CM}_{\mathrm{g}}$, respectively. Effective MSCs commitment into osteoblastic lineage was checked on cross sections of embedded paraffin samples according to previously published procedure (Mechiche Alami et al., 2017). Alizarin red staining was performed on consecutive tissue sections and images were taken using scanner iScan Coreo AU (Roche ${ }^{\circledR}$, Ventana). For immunohistochemistry, after deparaffinization, $4 \mu \mathrm{m}$ sections were incubated with the Cell Conditioner 1 (EDTA, pH 8.4) for $64 \mathrm{~min}$, followed by preprimary peroxidase inhibition and incubation with the primary rabbit polyclonal antibody targeting osteocalcin (at a $1 / 100$ dilution, Calbiochem) at $37^{\circ} \mathrm{C}$ overnight. Then, the staining reaction was performed using the UltraView Universal DAB v3 Kit (Ventana Medical System). Images were taken using scanner iScan Coreo AU.

\section{Human Umbilical Cord Vein Endothelial Cells (HUVECs)}

HUVECs were enzymatically isolated from fresh human umbilical cords veins obtained after full-term births following Jaffe et al., method (Rammal et al., 2017b). HUVECs were amplified at a density of $10^{4} \mathrm{cell} / \mathrm{cm}^{2}$ in endothelial basal medium (EBM)-2 supplemented with 20\% decomplemented FBS, $1 \%$ Penicillin/Streptomycin/Amphotericin B and 1\% Glutamax ${ }^{\circledR}$ $(v / v$, Gibco $)$ and maintained in a humidified atmosphere of $5 \%$ $\mathrm{CO}_{2}$ at $37^{\circ} \mathrm{C}$ with a medium change every 2 days. At the second passage, HUVECs were cultured in 12 well plates at $10^{4} \mathrm{cells} / \mathrm{cm}^{2}$ in the presence of diluted $\mathrm{CM}_{\mathrm{B}-\mathrm{MM}}$, and $\mathrm{CM}_{\mathrm{g}}$ (1:1 in EBM-2) for $48 \mathrm{~h}$. HUVECs stimulated with recombinant human Tumor Necrosis Factor $\alpha$ (TNF $\alpha$, R\&D Systems) at $10 \mathrm{ng} / \mathrm{mL}$ for $48 \mathrm{~h}$ were used as inflammatory positive control. After $48 \mathrm{~h}$, culture media were collected, centrifuged at $300 \mathrm{~g}$ and stored at $-80^{\circ} \mathrm{C}$. For a better comprehension, culture media of $\mathrm{CM}_{\mathrm{B}-\mathrm{MM}}$ and $\mathrm{CM}_{\mathrm{g}}$ stimulated HUVECs were designated as $\mathrm{EC}-\mathrm{CM}_{\mathrm{B}-\mathrm{MM}}$ and EC-CMg, respectively.

\section{Human Mandibular Pre-osteoblasts (OBs)}

Human mandibular bone specimens without any clinical or radiographic evidence of pathology were obtained from young patients (aged 13-33 years) undergoing windows teeth extraction oral surgery. After extensive (four to five times) washing steps, bone specimens were scraped to remove attached soft tissue and periosteum, broken into small pieces and predigested for $1 \mathrm{~h}$ with trypsin-EDTA $(0.5 \%, v / v) / \mathrm{B}$ collagenase $(1 \mathrm{mg} / \mathrm{mL})$ in a serum-free Dulbecco's Modified Eagle medium (DMEM). Fragments were then placed into $25 \mathrm{~cm}^{2}$ tissue culture flask and maintained in a humidified atmosphere of $5 \% \mathrm{CO}_{2}$ at $37^{\circ} \mathrm{C}$, allowing thus $\mathrm{OBs}$ migration and proliferation in the presence of DMEM supplemented with 20\% FBS and 1\% Penicillin/Streptomycin ( $v / v$, Gibco). OBs were then amplified at a density of $10^{4} \mathrm{cell} / \mathrm{cm}^{2}$ in $10 \%$ FBS supplemented DMEM with a medium change twice/week and used at the third passage in our experimental study design. At the third passage, OBs were cultured in 24 well plates at $10^{4}$ cells $/ \mathrm{cm}^{2}$ in the presence of diluted $\mathrm{CM}_{\mathrm{B}-\mathrm{MM}}, \mathrm{CM}_{\mathrm{g}}, \mathrm{EC}-\mathrm{CM}_{\mathrm{B}-\mathrm{MM}}$, and $\mathrm{EC}-\mathrm{CM}_{\mathrm{g}}(1: 1$ in DMEM) for 7 days. OB maintained in basal and osteogenic media (i.e., DMEM supplemented with $10 \mathrm{mM} \beta$-glycerophosphate, $250 \mu \mathrm{M}$ L-ascorbic acid 2-phosphate and $5 \mathrm{nM}$ dexamethasone) were used as controls.

\section{Co-culture of Human Neutrophils With HUVECs}

Neutrophils were purified from human whole blood collected on EDTA (BD Vacutainer ${ }^{\circledR}$ K2E, Franklin Lakes, USA) using the Polymorphprep ${ }^{\mathrm{TM}}$ protocol. Contaminating red blood cells were removed by a hypotonic shock. Resulting neutrophils were resuspended in complete RPMI 1640 media supplemented with $1 \%$ Penicillin/Streptomycin and 2.5\% heat-inactivated 
autologous human serum and represented $>97 \%$ of the cells. The PMNs were at least $95 \%$ viable. One million of neutrophils was finally brought in contact with un-stimulated and stimulated HUVECs (i.e., incubated for $48 \mathrm{~h}$ with $\mathrm{CM}_{\mathrm{B}-\mathrm{MM}}$ and $\mathrm{CM}_{\mathrm{g}}$ ).

\section{ELISA Cytokines, Chemokines, and Growth Factors Release}

Secreted levels, in MSCs culture media $\left(\mathrm{CM}_{\mathrm{B}-\mathrm{MM}}\right.$ and $\mathrm{CM}_{\mathrm{g}}$ ), of IL-1 $\beta$, IL-6, IL-8, IL-10, transforming growth factor (TGF- $\beta$ ), osteoprotegerin (OPG), Prostaglandin $\mathrm{E}_{2}\left(\mathrm{PGE}_{2}\right)$, receptor activator of nuclear factor kappa-B ligand (RANKL), hepatocyte growth factor (HGF), vascular endothelial growth factor (VEGF), fibroblast growth factor (b-FGF), and bone morphogenic protein-2 (BMP-2) were assessed. ELISA MAX $^{\mathrm{TM}}$ Deluxe kit for human IL-6, IL8, IL-10, and b-FGF (BioLegend), DuoSet ELISA Kit for human IL-1 $\beta$, TGF- $\beta$, Osteoprotegerin/TNFRSF11B, TRANCE/RANKL/TNFSF11, HGF, VEGF, and BMP-2 (R\&D Systems, France) and PGE-2 ELISA Kit (Cayman Chemical) were used. Absorbance was measured according to the manufacturers' instructions.

\section{Transwell Migration Assay}

HUVECs were seeded on the top of a cell culture insert membrane (Millicell ${ }^{\circledR}$ Hanging Cell Culture Inserts) at the density of $2 \times 10^{3}$ cells/well. MSCs culture media $\left(\mathrm{CM}_{\mathrm{B}-\mathrm{MM}}\right.$ and $\mathrm{CM}_{\mathrm{g}}$ ) were deposited in the bottom of a 24 well plastic culture plate. After $48 \mathrm{~h}$ of incubation at $37^{\circ} \mathrm{C}$ in $5 \% \mathrm{CO}_{2}$, non-migrating HUVECs were removed from the top of the membrane and migrated cells at the bottom of the insert membrane were fixed with methanol then stained with crystal violet. Migrated cells were finally imaged using EVOS $^{\circledR}$ digital microscope and counted. EBM-2 and $\alpha-M E M \pm 10 \%$ FBS were used as controls.

\section{PCR Gene Expression Analysis}

For $\mathrm{CM}_{\mathrm{B}-\mathrm{MM}}$ and $\mathrm{CM}_{\mathrm{g}}$ stimulated HUVECs and $\mathrm{OBs}$ as well as $\mathrm{EC}-\mathrm{CM}_{\mathrm{B}-\mathrm{MM}}$ and $\mathrm{EC}-\mathrm{CM}_{\mathrm{g}}$ stimulated $\mathrm{OBs}$ (Figure 1, study experimental design), total RNA was isolated and purified using MasterPure ${ }^{\mathrm{TM}}$ RNA Purification Kit (Epicenter ${ }^{\circledR}$ Biotechnologies) in accordance with the manufacturer protocol. RNA purity was assessed by measuring the absorbance ratio at 260/280 nm (Nanodrop 2000C, ThermoScientific), which was comprised between 1.8 and 2. Total RNAs (500 ng) were reverse transcribed into cDNA using a High Capacity cDNA Reverse Transcription kit (Applied Biosystems) following manufacturer instructions. Ten nanograms of reverse transcription product were amplified by qRT-PCR on a StepOnePlus ${ }^{\text {TM }}$ system (Applied Biosystems). Using this approach, the transcriptional levels of RPS18 (internal control), TNF $\alpha, I L-6, I L-8, S E L E, I C A M 1$, and $B M P-2$ mRNA in stimulated HUVECs and the transcriptional levels of HPRT-1 (internal control), COL1A1, and BGLAP mRNA in stimulated OBs were determined using Power SYBR ${ }^{\circledR}$ Green PCR Master MIX (Applied Biosystems) and TaqMan ${ }^{\circledR}$ Fast Advanced Master Mix (Applied Biosystems) for ALPL and Runx2 mRNA. After a first denaturation step at $95^{\circ} \mathrm{C}$ for $10 \mathrm{~min}, \mathrm{qRT}-\mathrm{PCR}$ reactions were performed according to a thermal profile that corresponds to 40 cycles of denaturation at $95^{\circ} \mathrm{C}$ for $15 \mathrm{~s}$, annealing and extension at $60^{\circ} \mathrm{C}$ for $1 \mathrm{~min}$. Data analysis was performed with the StepOne ${ }^{\mathrm{TM}}$ Software v2.3 (Applied Biosystems).

\section{Scanning Electron Microscopy With a Field Emission Gun (FEG-SEM)}

Neutrophils adhered to stimulated HUVECs (i.e., incubated for $48 \mathrm{~h}$ with $\mathrm{CM}_{\mathrm{B}-\mathrm{MM}}$ and $\mathrm{CM}_{\mathrm{g}}$ ) were fixed with $2.5 \%(\mathrm{w} / \mathrm{v})$ glutaraldehyde (Sigma Aldrich) at room temperature for $1 \mathrm{~h}$. Samples were dehydrated in graded ethanol solutions from 50 to $100 \%$ and desiccated in hexamethyldisilazane (Sigma Aldrich) for $10 \mathrm{~min}$. After air-drying at room temperature, samples were sputtered with a thin gold-palladium film under a JEOL ion sputter JFC 1100 and viewed using FEG-SEM (JEOL JSM-7900F). Images were acquired from secondary electrons at primary beam energy between 5 to $20 \mathrm{kV}$.

\section{Mitochondrial Activity}

WST-1 cell proliferation assay (Roche Diagnostics) was performed on human mandibular osteoblasts (OBs) cultured in MSC $\left(\mathrm{CM}_{\mathrm{B}-\mathrm{MM}}\right.$ and $\left.\mathrm{CM}_{\mathrm{g}}\right)$ and stimulated HUVECs (EC$\mathrm{CM}_{\mathrm{B}-\mathrm{MM}}$ and $\mathrm{EC}-\mathrm{CM}_{\mathrm{g}}$ ) culture media for 2, 4, and 7 days. Absorbance was measured at $440 \mathrm{~nm}$ using a FLUOstar Omega microplate reader (BMG Labtech) against a background control as blank. A wavelength of $750 \mathrm{~nm}$ was used as the correction wavelength. Mitochondrial activity, an indicator of cell viability, was calculated as the absorbance ratio between stimulated and basal culture medium (considered as $100 \%$ of viable osteoblasts).

\section{Statistical Analysis}

All MSCs experiments were performed with six independent umbilical cords. HUVECs, OBs, and neutrophils, were performed with three independent donors. ELISA and PCR results are presented as box plot chart with median using GraphPad ${ }^{\circledR}$ Prism 5 software. Multivariate statistical analysis was performed by XL Stat software. Metabolic activity results are presented as histograms with mean \pm standard error of the mean. All statistical analysis were performed using GraphPad ${ }^{\circledR}$ Prism 5 software. For Mann Whitney test, a value of $p<0.05$ was accepted as statistically significant $p$ (rejection level of the null-hypothesis of equal medians).

\section{RESULTS AND DISCUSSION}

We recently reported that intrinsic features of bone-mimetic material (B-MM) made from inorganic calcium phosphate supplemented with chitosan and hyaluronic acid biopolymers influences MSCs fate through mechanobiological pathway, inducing the expression of bone specific proteins (up to 1 week) (Rammal et al., 2017a). Bone develops through a tightly regulated process leading to a hierarchically ordered three-dimensional structure described in the literature as 

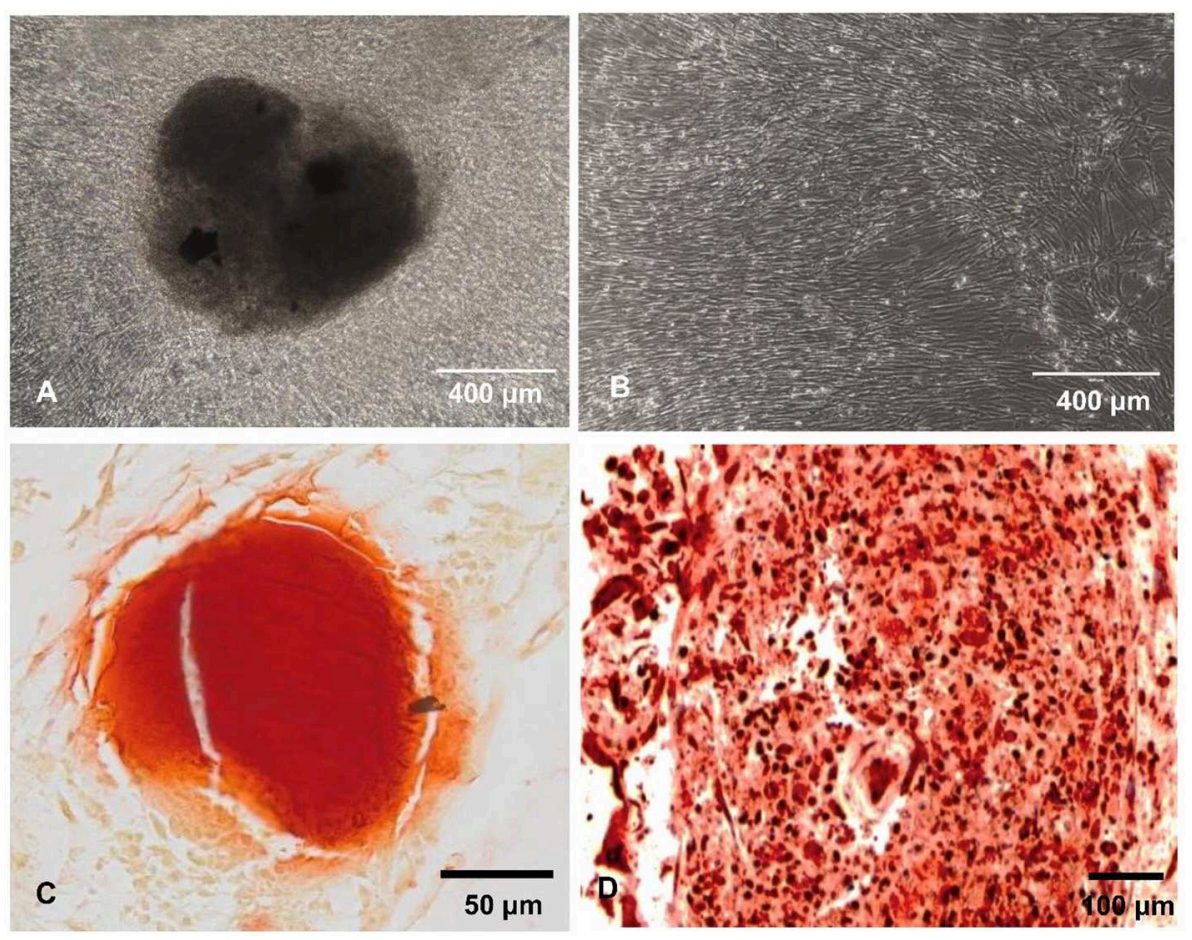

FIGURE 2 | MSCs behavior. (A,B) Representative optical images showing MSCs accretions on bone-mimetic material (A) and cellular layer on glass (B) (scale bar $400 \mu \mathrm{m}$ ). (C) Red alizarin histological staining and (D) osteocalcin immunohistochemistry (scale bars 50 and $100 \mu \mathrm{m}$, respectively), demonstrating the bone-like nodule formation on B-MM.

bone nodule (Mechiche Alami et al., 2016). Starting from day 14, MSCs cultured on B-MM formed 3D nodules in some distinct region (about $8 \%$ of the cultured area), whereas on control glass coverslip, no major morphological changes and no nodules were observed Histological and immunohistochemical analysis of paraffin-embedded nodules evidenced the presence of mineralized matrix positive to red alizarin and cells positive to osteocalcin (Figure 2 and Figure S1). A deeper characterization of these bone-like nodules would require multiscale investigations (Gentleman et al., 2009) that are out of scoop of the present study. The nodule density of around $9 \pm 2$ nodules in the cultured area suggests a low commitment of MSCs into osteoprogenitor cells. These observations are consistent with other studies highlighting a very low yield of MSCs able to differentiate into osteoblastic lineage (Jin and Lee, 2018; Golchin and Farahany, 2019). Along their capacity to differentiate into desired phenotype, MSCs contribute to tissue regeneration through the secretion of soluble and insoluble mediators (Glenn and Whartenby, 2014; Wang et al., 2014; Haumer et al., 2018; Najar et al., 2018). Focusing our investigations on the secretion of soluble mediators required for bone regeneration, the paracrine activity of MSCs cultured on B-MM was analyzed and compared to glass (Figure 3A, experimental design). ELISA results showed that MSCs cultured on B-MM decreased significantly the secretion of IL-1 $\beta$, IL- 6 , and IL- 8 pro-inflammatory mediators $(\approx 5-, 4-$, and 2-fold vs. glass, $p<0.01, p=0.007$ and $p<$ 0.04 , respectively, Mann Whitney test) but increased significantly
PGE-2 production $(\approx 1.37$-fold vs. glass, $p<0.01$, Mann Whitney test) (Figure 3B). TNF- $\alpha$ and RANKL were below the detection limit while the constitutive production of OPG was found to be not sensitive to culture substrate (Figure 3B). These mediators have great potential in bone repair and homeostasis (Raisz, 1999; Kon et al., 2001; Marsell and Einhorn, 2011; Sugimoto et al., 2016; Lin et al., 2018), but at high level, IL-1 $\beta$, IL-6, IL-8, TNF- $\alpha$, and soluble RANKL could be involved in osteoclast activation, bone destruction and ineffective regeneration (Mountziaris and Mikos, 2008). MSCs secrete various soluble growth factors to promote bone formation (TGF- $\beta$, VEGF and BMPs) and vascularization (HGF, b-FGF, VEGF) (Gerber et al., 1999; Tang et al., 2009; Chim et al., 2013; Crane et al., 2016). While the secretion of TGF- $\beta$ and HGF was unchanged, the production of VEGF and b-FGF was significantly increased on B-MM $(\approx 4.5$ - and 36fold vs. glass, $p<0.001$, Mann Whitney test). Surprisingly BMP-2 was not detected in MSCs supernatants (Figure 3B). Bone extracellular matrix (ECM) may not only sequester and store soluble BMPs but also expose them to OBs receptors; explaining away the lack of soluble BMP-2 detection in culture media (Chim et al., 2013). Despite its inability to induce MSCs osteogenic commitment, TGF- $\beta$ promotes the recruitment and proliferation of osteoprogenitors during bone healing process (Chim et al., 2013). VEGF and b-FGF are known to promote ECs migration and tissue vascularization and indirectly OBs migration, proliferation, and differentiation (Gerber et al., 1999; Tang et al., 2009; Chim et al., 2013). Taken together, these results 


\section{A Experimental setup}

MSCs

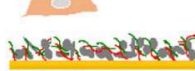

B-MM

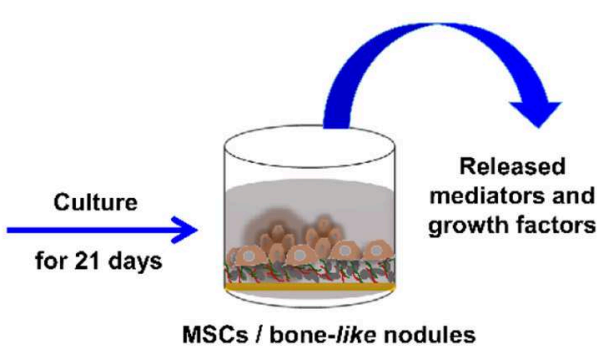

B ELISA experiments
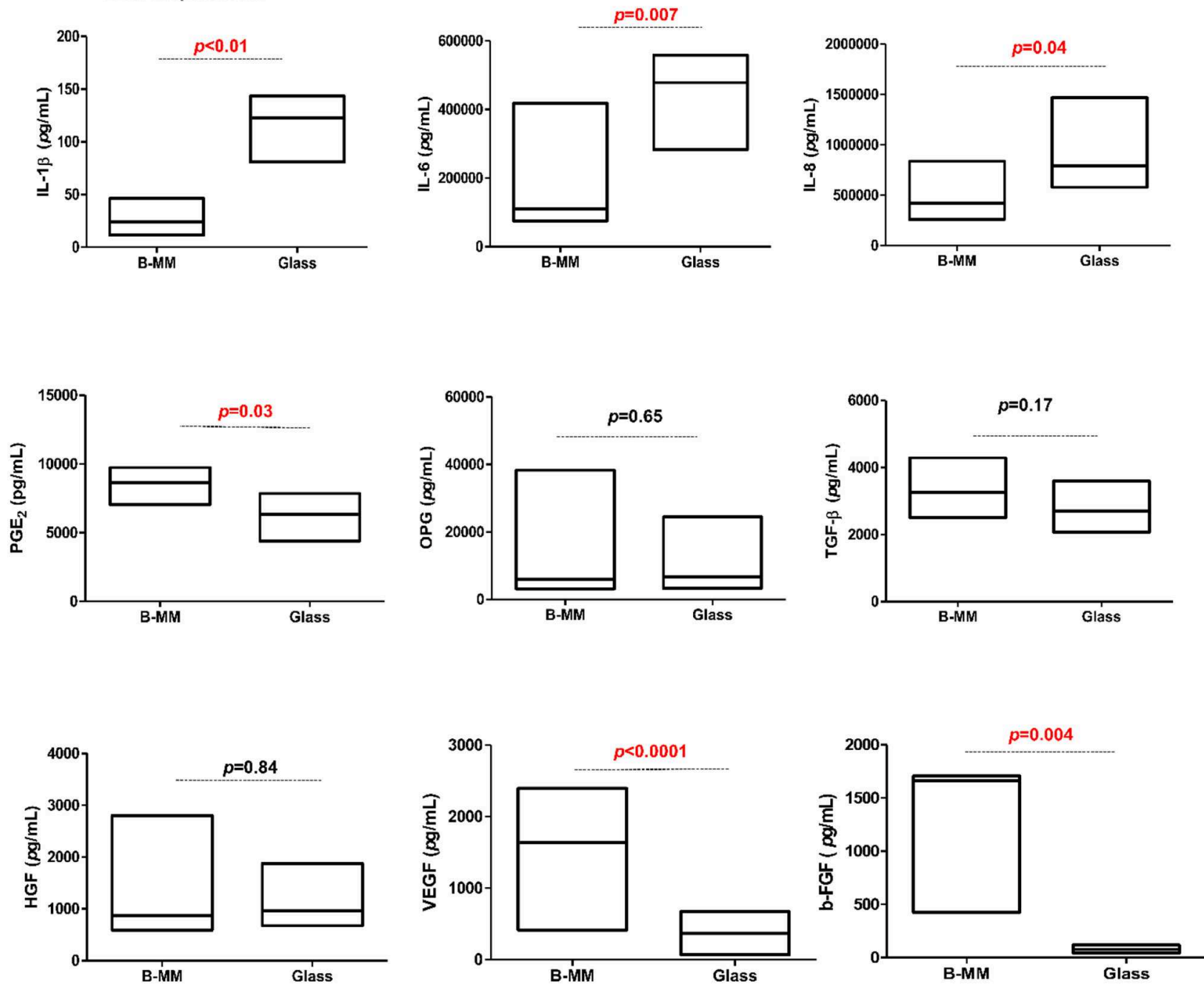

FIGURE 3 | Cytokines, chemokines, and growth factors production. (A) Experimental setup and (B) Released IL-1 $\beta$, IL-6, IL-8, PGE-2, OPG, TGF- $\beta$, HGF, VEGF, and b-FGF quantified by ELISA, indicating a down production of inflammatory mediators and up release of angiogenic mediators by MSCs cultured on bone-mimetic material (B-MM) compared to glass ( $n=6$, Mann Whitney test). TNF- $\alpha$, IL-10, soluble RANKL, and BMP-2 were not detected in MSCs media.

suggest that the paracrine activities of MSCs cultured on BMM seems to be imbalanced in favor of vasculogenesis rather than osteogenesis. This conclusion was supported by principal component analysis (Wu et al., 2016) that showed data variance superior to $60 \%$ (Figure 4A). It appears that b-FGF, VEGF, HGF, TGF- $\beta$, OPG as well as PGE-2 are closer to MSCs on B-MM whereas IL-1 $\beta$, IL-6, and IL- 8 are closer to MSCs on glass. Discrimination of secretory activity was not affected by donor 


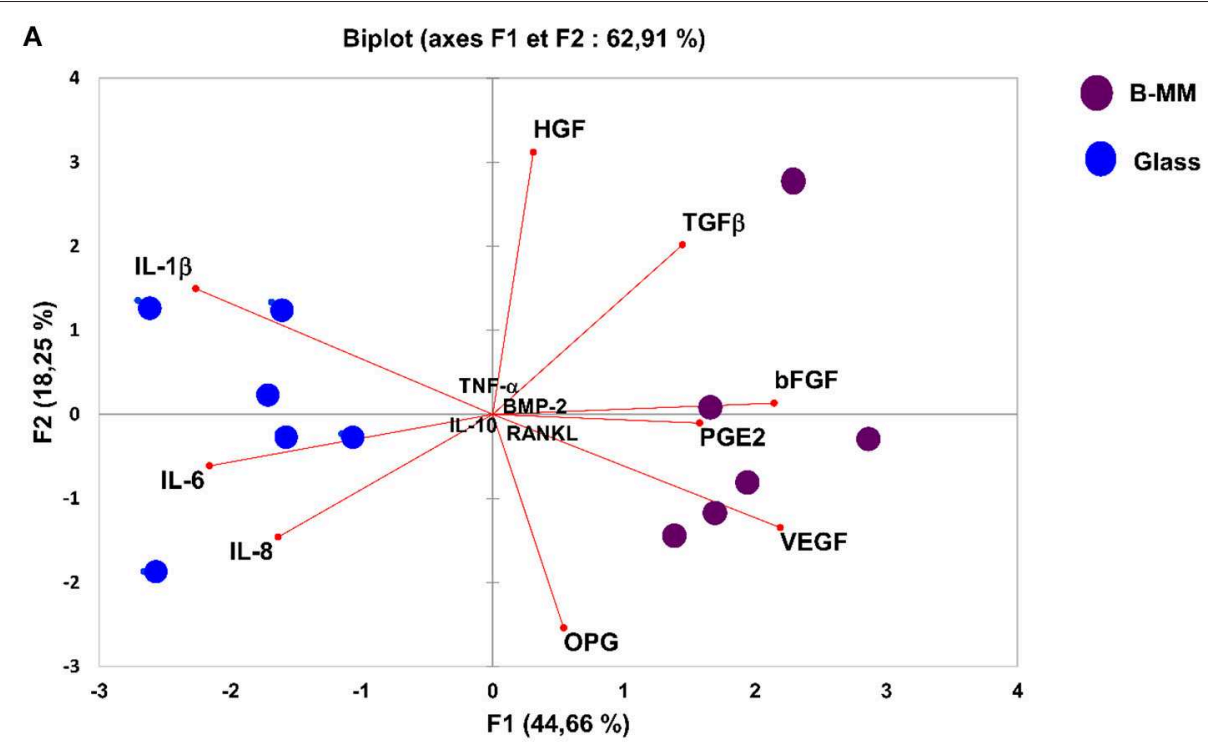

B

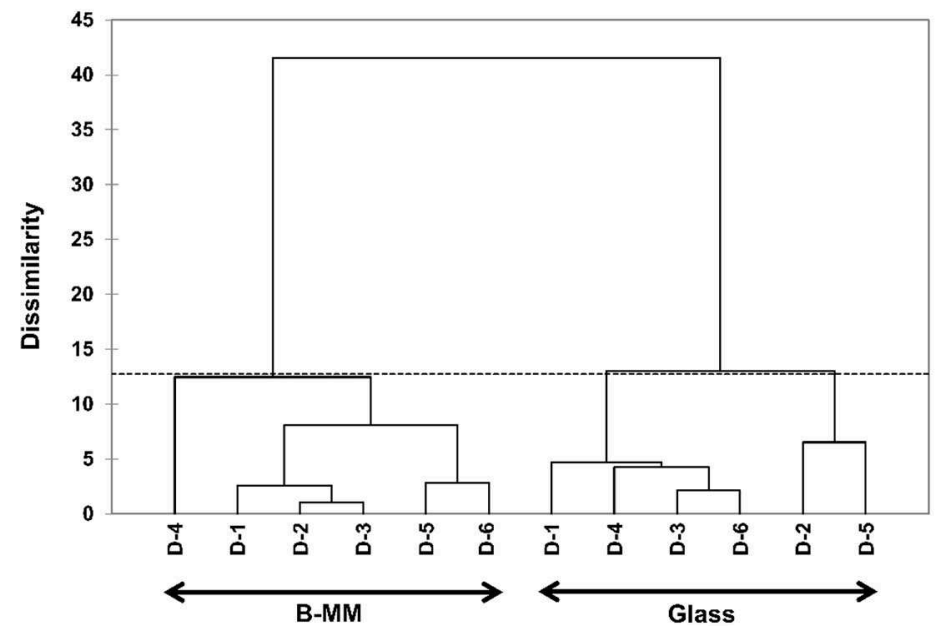

FIGURE 4 | Multivariate statistical analysis. (A) Principal Component Analysis (PCA) plots and (B) Dendrogram, indicating, despite donor (D) variability, a clear separation between the averages of secreted mediators by MSCs cultured on bone-mimetic material (B-MM) and on glass.

variability but resulting differences were due to MSCs behavior once on B-MM or glass substrate (Figure 4B).

\section{Indirect MSCs/Endothelial Cells (ECs) Crosstalk}

The crosstalk between MSCs/OBs/ECs is essential for bone formation and remodeling as well as around implanted graft during bone repair (Helmy et al., 2012). Above results suggest that MSCs cultured on B-MM could have a great potential in boosting ECs migration and proliferation (Gerber et al., 1999; Mountziaris and Mikos, 2008). To evaluate the effect of MSCs cultured on B-MM on ECs migration, transwell chemotaxis assay was performed. MSCs culture media (MSCsCM) harvested between 19th and 21st day of culture and primary HUVECs were used (Figure 5A, experimental design).
For better comprehension, we designated culture media from MSCs cultured on B-MM and on glass by $\mathrm{CM}_{\mathrm{B}-\mathrm{MM}}$ and $\mathrm{CM}_{\mathrm{g}}$, respectively. $\mathrm{CM}_{\mathrm{B}-\mathrm{MM}}$ enhanced significantly HUVECs recruitment with about $50 \%$ of migrated HUVECs whereas $\mathrm{CM}_{\mathrm{g}}$ recruited only $2 \%$ (Figure $5 \mathbf{B}$ ), confirming the superior chemotactic activity of MSCs on B-MM compared to glass.

Upon bone graft implantation, recruited leukocytes secrete an array of pro-inflammatory cytokines and growth factors, orchestrating the graft integration into host bone tissue (Luu et al., 2013). ECs through the expression of adhesion molecules and the release of inflammatory cytokines, constitute the main regulators of leukocyte recruitment (Ucuzian and Greisler, 2007; McGettrick et al., 2012). In contrast to differentiated MSCs, naïve cells, mainly through IL- 6 and TGF- $\beta$ release, are 

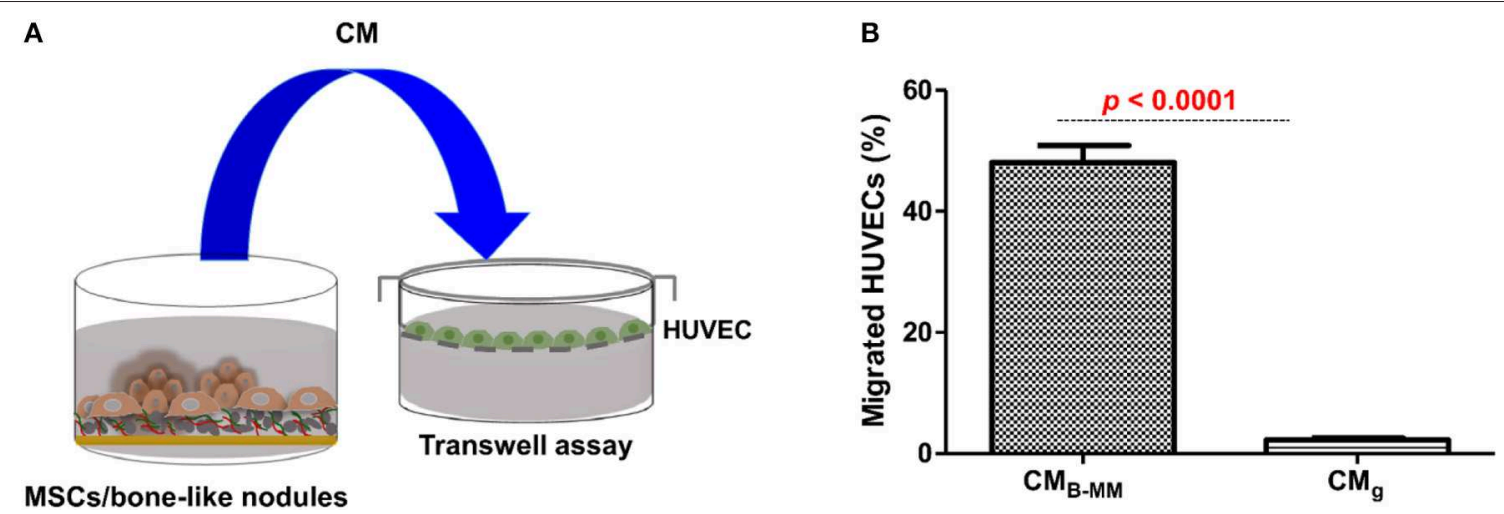

FIGURE 5 | Endothelial cell recruitment. (A) Experimental design and (B) Transwell chemotaxis assay, showing a significant increase in endothelial cell migration in presence of MSCs culture media (MSCs-CM) in presence of bone-mimetic material (B-MM) compared to glass (for MSCs and HUVECs, $n=6$ and 3 , respectively, Mann Whitney test).

known to regulate leukocyte diapedesis (Ucuzian and Greisler, 2007). Although B-MM slightly increased TGF- $\beta$ release, above cited results indicated a significant decrease in IL-6 production (Figure 3B), suggesting a potential indirect effect on leukocyte recruitment. Thus, a second set of experiments was conducted to investigate the latter hypothesis. HUVECs were incubated with $\mathrm{CM}_{\mathrm{B}-\mathrm{MM}}$ and $\mathrm{CM}_{\mathrm{g}}$ for $48 \mathrm{~h}$ and $\mathrm{qRT}-\mathrm{PCR}$ experiments were conducted to assess HUVECs inflammatory phenotype through gene regulation of TNFA, IL6, IL8, SELE, and ICAM1 (Figure 6A, experimental design). Note that once stimulated, ECs kept their characteristic cobblestone morphology (Figure 6B). Compared to un-stimulated HUVECs (i.e., cultured in endothelial basal medium), qRT-PCR results revealed an up-regulation of all studied genes in $\mathrm{CM}_{\mathrm{B}-\mathrm{MM}}$ and $\mathrm{CM}_{\mathrm{g}}$ stimulated HUVECs (at least an up-regulation of $\left.2^{-\Delta \Delta \mathrm{CT}}\right)$, signature of inflammatory phenotype. Regardless ECs inflammatory phenotype and compared to TNF- $\alpha$ stimulus (positive inflammatory control), MSCs-CM had a lower inflammatory impact on ICAM1, SELE, and TNFA, but up-regulated both IL6 and IL8. Interestingly, although no differences were observed for TNFA, IL6, IL8, and SELE, we noticed a significant over-expression of ICAM1 in presence of $\mathrm{CM}_{\mathrm{B}-\mathrm{MM}}\left(1.5\right.$-fold vs. $\mathrm{CM}_{\mathrm{g}}, \mathrm{p}<0.02$, Mann Whitney test, Figure 6C).

ICAM-1, constitutively expressed at low levels on ECs, can be up-regulated in response to pro-inflammatory stimuli, mediating neutrophil diapedesis (Anderson et al., 2008). Thus, adhesion of neutrophils to $\mathrm{CM}_{\mathrm{B}-\mathrm{MM}}$ and $\mathrm{CM}_{\mathrm{g}}$ stimulated HUVECs was followed. Whatever the studied condition, the cobblestone monolayer integrity was altered when neutrophils were added. SEM revealed that neutrophils, in close similarity with TNF- $\alpha$ stimulated HUVECs condition, exhibited membrane ruffling and vesicles, indicative of neutrophil activation in contact with $\mathrm{CM}_{\mathrm{B}-\mathrm{MM}}$ stimulated HUVECs; whereas in contact with $\mathrm{CM}_{\mathrm{g}}$ stimulated HUVECs, neutrophils, as for un-stimulated HUVECs condition, were rounded and appeared less activated (Figure 6D and Figure S2). Furthermore, a higher magnification of activated neutrophils in close contact to the apical part of HUVECs showed elongated neutrophils with long protrusions embracing HUVECs and forming adhesion points (Figure 6D, arrows). These observations corroborate previous studies, indicating that spreading can be signature of transmigrating neutrophils (Anderson et al., 2008; Schaefer et al., 2014).

Adding ECs to bone engineered constructs increases vascularization within and surrounding implanted constructs and boosts bone formation (Gerber et al., 1999; Von WedelParlow et al., 2011). In response to VEGF, ECs produce BMP-2 that stimulates OBs differentiation, promoting fracture healing (Zhang et al., 2018b). Regarding the significant increase in VEGF release by MSCs cultured on B-MM vs. glass (Figure 3B); the expression of BMP-2 by HUVECs was followed. Despite a significant $B M P 2$ up-regulation in $\mathrm{CM}_{\mathrm{B}-\mathrm{MM}}$ stimulated HUVECs $\left(\approx 5^{-\Delta \Delta C T}\right.$, Figure $6 \mathrm{C}$ ), released BMP-2 was not detected in the culture supernatant, suggesting that BMP-2 production is under the detection threshold of the kit or is accumulated within the cell cytoplasm. These results are consistent with other observations demonstrating that ECs require direct contact with bone marrow derived MSCs for the effective production of BMP-2 (Kaigler et al., 2005).

\section{Do MSCs Cultured on B-MM Promote Indirectly Pre-osteoblasts Differentiation?}

As shown above, IL-1 $\beta$, IL-6, IL-8, and VEGF secretion levels from MSCs cultured on B-MM were significantly modulated compared to glass (Figure 3B). These soluble factors are reported to mediate, in dose-dependent manner, pre-osteoblasts proliferation and differentiation (Mountziaris and Mikos, 2008). In the following, proliferation kinetic of human alveolar bone derived $\mathrm{OBs}$ cultured in presence of $\mathrm{CM}_{\mathrm{B}-\mathrm{MM}}$ and $\mathrm{CM}_{\mathrm{g}}$ was firstly investigated (Figure 7A, experimental design). When cultured in $\mathrm{CM}_{\mathrm{B}-\mathrm{MM}}$, the proliferation of OBs was significantly promoted compared to OBs cultured in osteogenic media (Figure S3). Moreover, we noticed a significant increase in MSCs-CM stimulated OBs proliferation from day 2 to 4 with a slow proliferation rate for $\mathrm{CM}_{\mathrm{g}}(p<0.0001$, Mann 


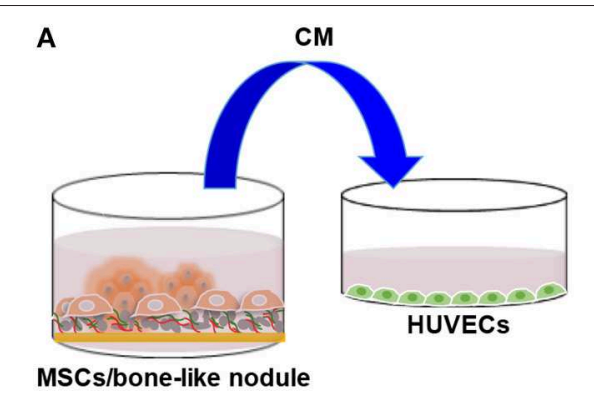

C
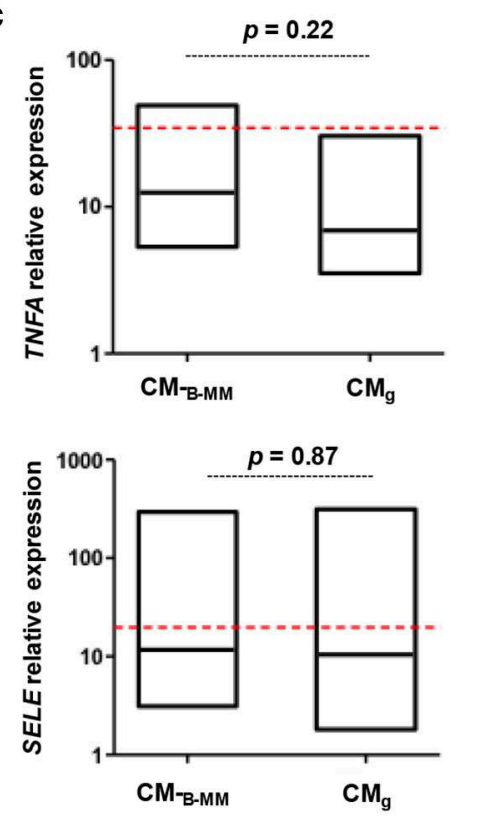

D

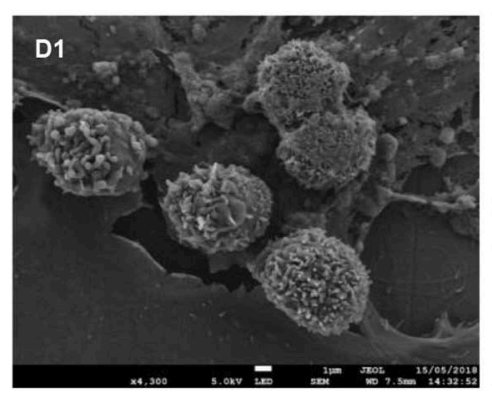

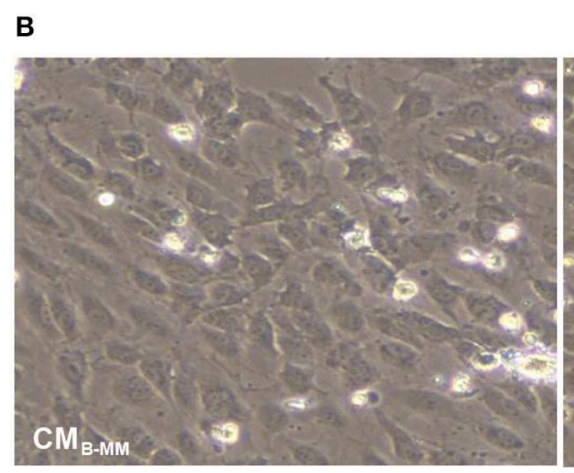
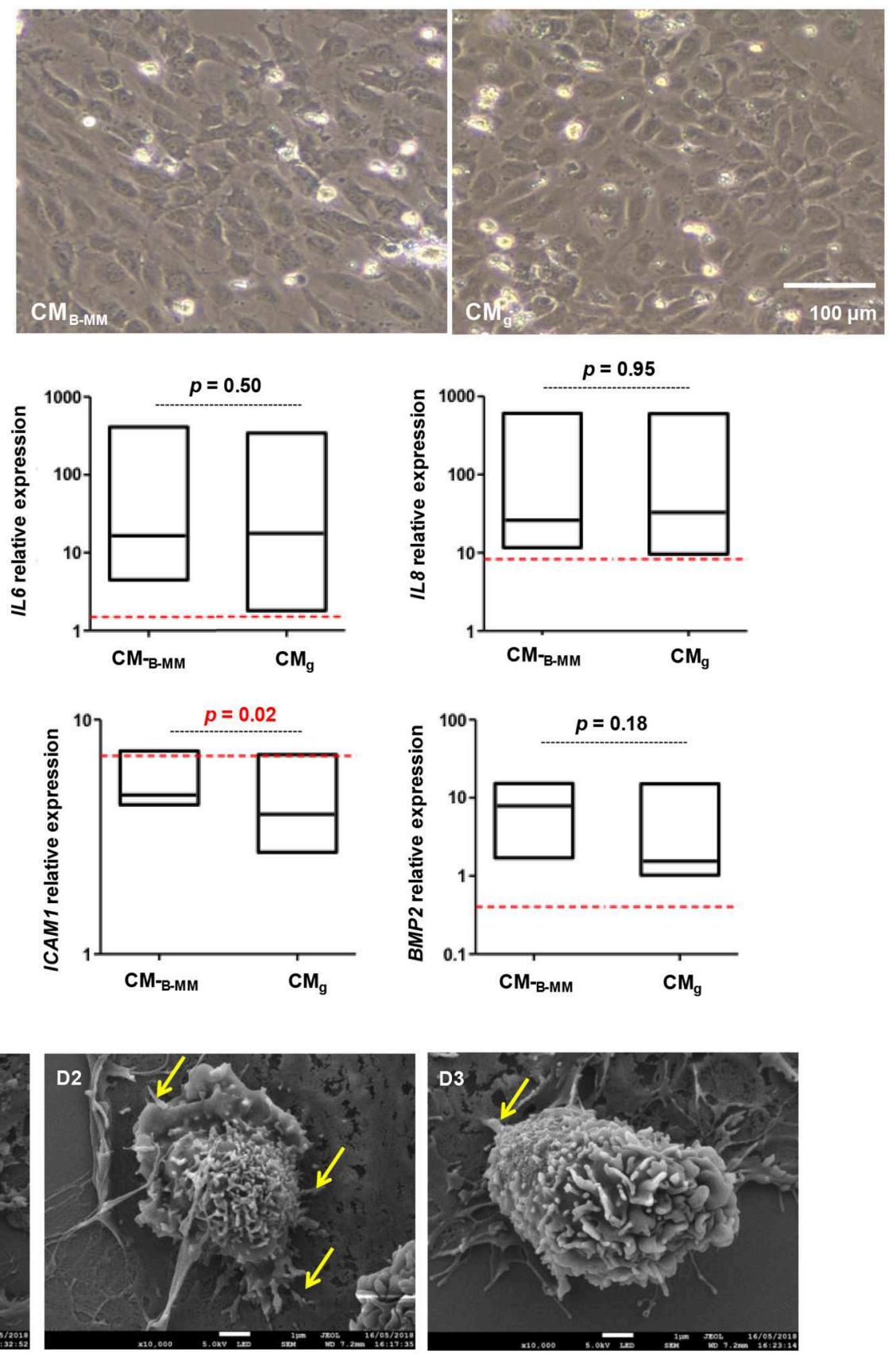

FIGURE 6 | Endothelial cell inflammatory phenotype. (A) Experimental design and (B) representative optical images of stimulated HUVECs by MSCs culture media (MSCs-CM $\mathrm{B}-\mathrm{MM}$ and MSCs-CMg, scale bar = $100 \mu \mathrm{m}$ ), highlighting a cobblestone morphology. (C) Gene expression of ICAM1, SELE, TNFA, IL6, IL8, and BMP2 quantified by qRT-PCR (red bars indicate TNF- $\alpha$ stimulated endothelial cells positive control) (for MSCs and HUVECs, $n=6$ and 3 , respectively, Mann Whitney test), showing a significant over-expression of ICAM1 in presence of $\mathrm{CM}_{\mathrm{B}-\mathrm{MM}}$. (D) Endothelial cell/neutrophil interaction imaged by scanning electron microscopy (Yellow arrows indicating neutrophil protrusion, scale bars $=1 \mu \mathrm{m}$ ), showing spread neutrophils with a transmigrating aspect in presence of $\mathrm{CM}_{\mathrm{B}-\mathrm{MM}}$.

Whitney test). Whatever the stimulus, a plateau appeared from day 4 to 7 (Figure 7B). No significant difference in OBs morphology was noticed among the studied conditions (Figure 7C), suggesting that MSCs-CM stimuli did not affect the cell cytoskeleton. Differentiation of OBs cultured in presence of MSCs-CM was secondly investigated. During the early stage of bone formation, the gene expression of Runx-2 and ECM proteins including COL-I is concomitant with OBs proliferation 
A

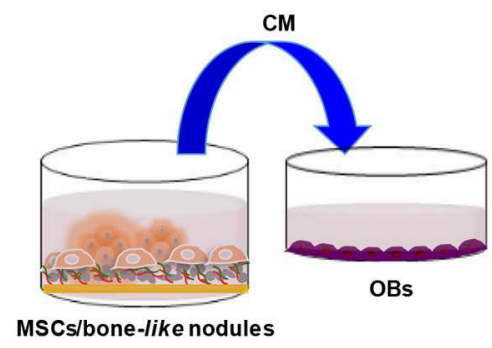

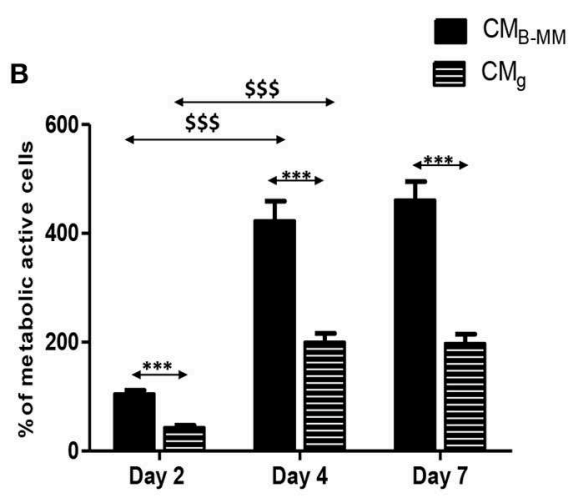

C
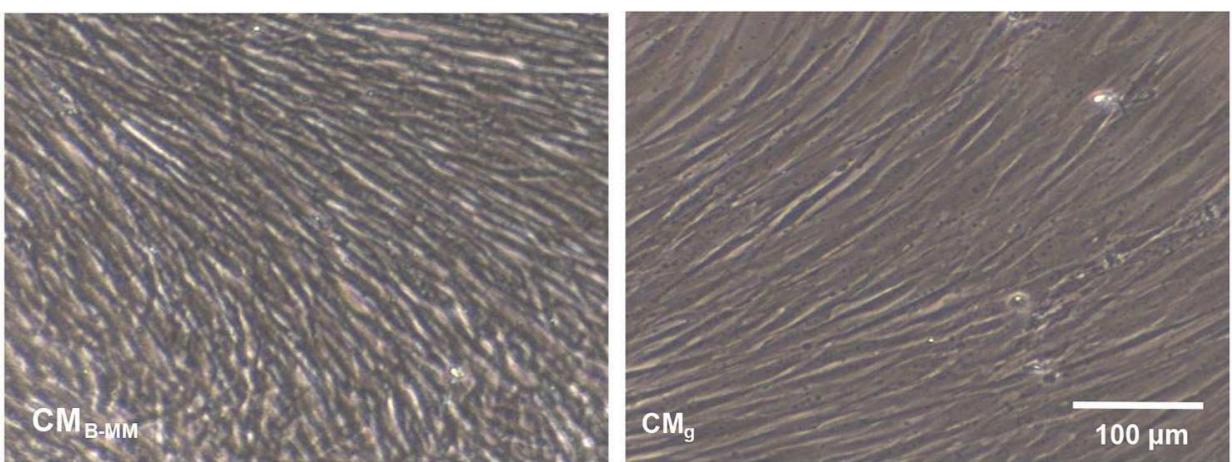

D
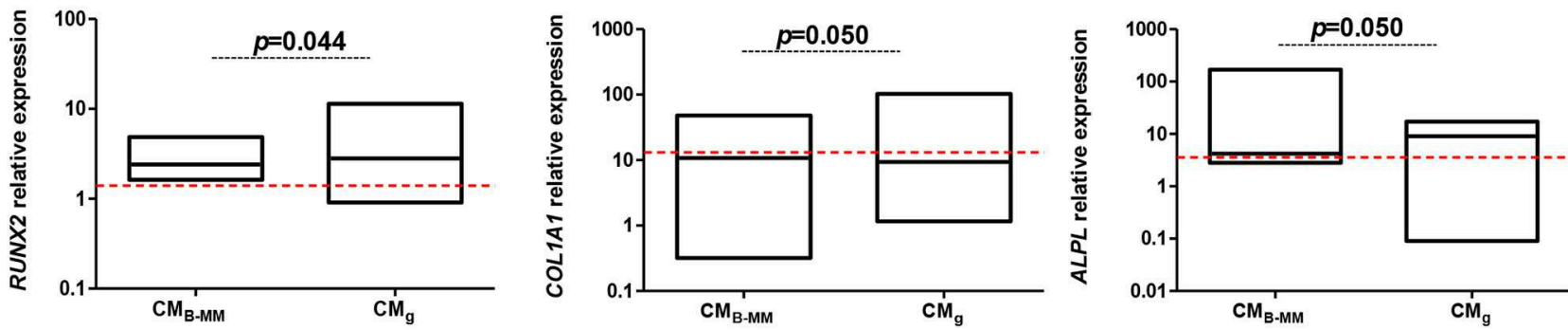

FIGURE 7 | Indirect MSCs/pre-osteoblasts crosstalk. (A) Experimental design and (B) pre-osteoblast (OBs) proliferation in presence of MSCs culture media (MSCs-CM). Results normalized to un-stimulated OBs, showing a significant increase in OB proliferation in presence of MSCs-CM cultured on bone-mimetic material compared to inert glass ( ${ }^{*} \mathrm{CM}$ B-MM vs. $\mathrm{CM}_{\mathrm{g}}$ and ${ }^{\$} \mathrm{D} 4$ and D7 vs. D2, for MSCs and OBs, $n=6$ and 3, respectively, Mann Whitney test). (C) Optical images of stimulated OBs after 7 days of culture in MSCs-CMB-MM and MSCs-CMg, indicating fibroblastic cell morphology (Scale bars = $100 \mu \mathrm{m}$ ). (D) Gene expression of RUNX2, COL1A1, and ALPL quantified by qRT-PCR (red bars indicates OBs cultured in presence of osteogenic media), indicating the absence of an effective osteoblastic differentiation in the studied conditions (for MSCs and OBs, $n=6$ and 3, respectively, Mann Whitney test). ${ }^{\star \star *}$ or $\$ \$ \$$ means $p<0.0001$. ${ }^{\star}$ is media dependent for the same kinetic time point and the $\$$ is kinetic time point dependent for the same media.

whereas the non-proliferative and immature OBs up-regulate certain genes such as alkaline phosphatase $(A L P L)$, a specific enzyme involved in the mineralization process. The late stage of bone formation corresponds to matrix mineralization, which is characterized by an up-regulation of non-collagenous proteins such as osteocalcin (BGLAP) (Mechiche Alami et al., 2017). While MSCs-CM stimulated the OBs proliferation, we failed to observe their effective differentiation (Figure 7D). Indeed, as for OBs cultured in osteogenic media, qRT-PCR experiments showed that both MSCs-CM up-regulate the expression levels of RUNX2, COL1A1, and ALPL over the time, however no statistically significance was distinguished between the studied conditions. Furthermore, no boosting effect of OBs differentiation was observed as BGLAP, late bone specific marker, was not detected.

\section{Do MSC-CM Stimulated HUVECs Boosts Pre-osteoblasts Differentiation?}

The intimate association between ECs and OBs suggests that ECs are to be prime sources for bone development (Gerber et al., 1999). In this part of the study, we assessed the effect of stimulated HUVEC supernatant (ECs-CM) on OBs (Figure 8A). As noticed above, we had a significant increase in OBs proliferation from day 2 to 4 with plateau from day 4 to 7 


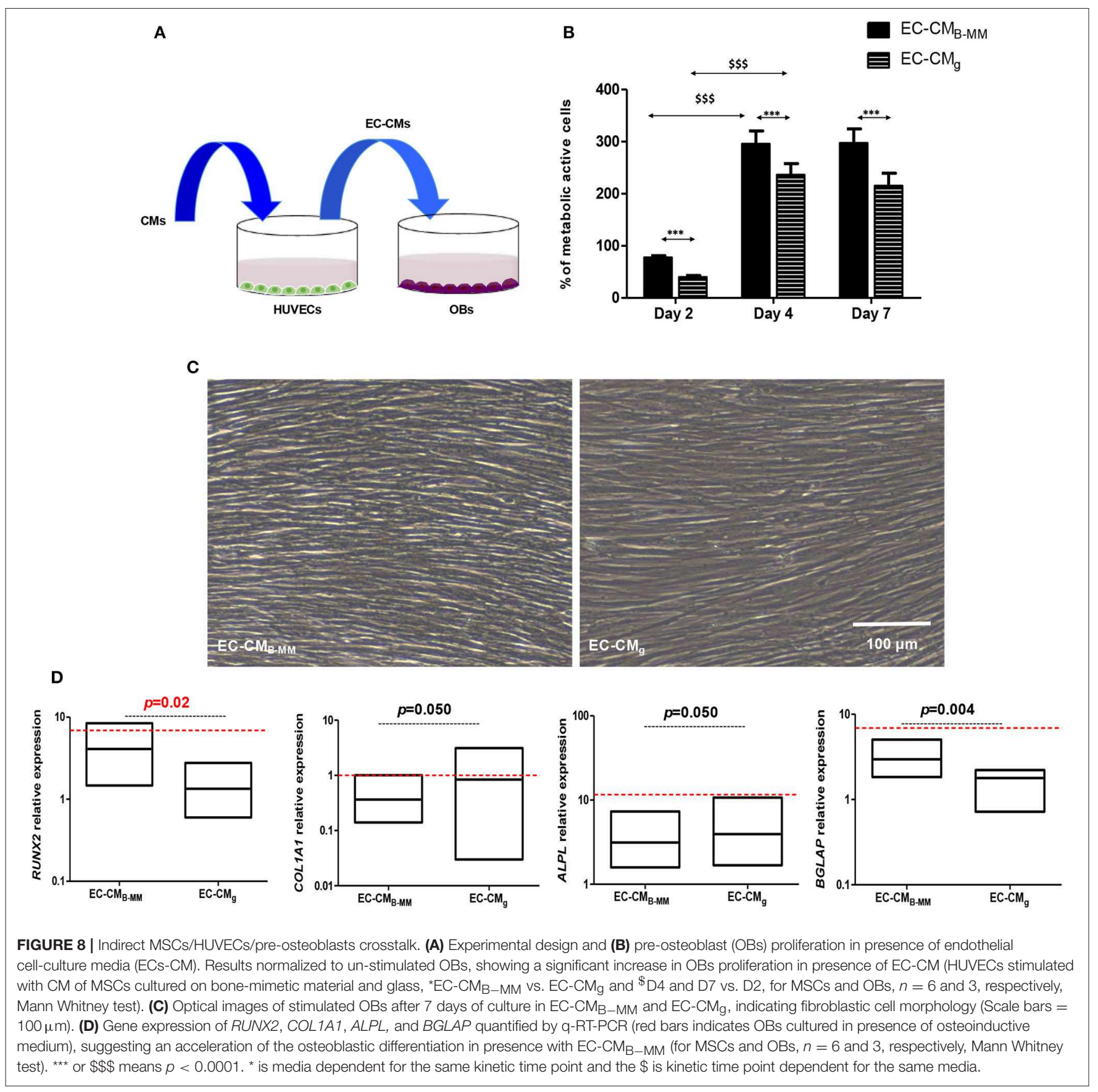

without changes in cell morphology (Figures 8B,C). However, proliferation rate of OBs seemed slower in presence of ECsCM compared to MSCs-CM $(\approx 300$ vs. $450 \%$ after 4 days of culture). Investigating the OBs differentiation in presence of ECs-CM, qRT-PCR experiments showed a down regulation of COL1A1 and ALPL concomitantly to an up-regulation of RUNX2 and BGLAP after 7 days (Figure 8D). Thus, despite the absence of BMP-2 release by HUVECs, compared to $\mathrm{CM}_{\mathrm{g}}$, $\mathrm{CM}_{\mathrm{B}-\mathrm{MM}}$ stimulated ECs up-regulated significantly RUNX2 and BGLAP in OBs, suggesting a potential acceleration of OB differentiation.

\section{CONCLUSION AND PERSPECTIVES}

Herein we show that MSCs cultured on osteoinductive BMM formed bone-like nodules. These nodules, arising from MSCs fibroblastic layers, occupied only $8 \%$ of cultured area. Despite the small fraction of committed osteoprogenitors, B-MM decreased the production of IL- $1 \beta$, IL- 6 , and IL-8 inflammatory mediators and increased the release of b-FGF, VEGF angiogenic growth factors. Compared to $\mathrm{CM}_{\mathrm{g}}, \mathrm{CM}_{\mathrm{B}-\mathrm{MM}}$ enhanced endothelial cell migration and neutrophil diapedesis via ICAM1 up-regulation. Regarding osteogenesic capacities, 
both $\mathrm{CM}_{\mathrm{B}-\mathrm{MM}}$ and $\mathrm{CM}_{\mathrm{g}}$ failed to boost pre-osteoblast differentiation. Interestingly, $\mathrm{EC}-\mathrm{CM}_{\mathrm{B}-\mathrm{MM}}$ up-regulated BGLAP expression, suggesting an acceleration of pre-osteoblast maturation. Our results showed that BMP-2 seemed not responsible for ECs osteogenic property, suggesting the implication of other mediators. A deeper characterization (i.e., microarray analysis) of collected media is required to highlight the implication of other factors. MSCs and ECs are known to release therapeutic microvesicles that can act in a paracrine manner on tissue healing (Kaigler et al., 2005; Behera and Tyagi, 2018). Thus, it will be interesting to investigate the potential contribution of B-MM on microvesicles production and features.

\section{DATA AVAILABILITY STATEMENT}

All data generated or analyzed during this study are included in this published article (and its Supplementary Information Files). If not, they are available from the corresponding author on reasonable request.

\section{ETHICS STATEMENT}

The studies involving human participants were reviewed and approved by our local Research Institution and were conducted with informed patients (written consent) in accordance with the usual ethical legal regulations (Article $\mathrm{R}$ 1243-57). All procedures were done in accordance with our authorization and registration number DC-2014-2262 given by the National Cellule de Bioéthique. The patients/participants provided their written informed consent to participate in this study.

\section{REFERENCES}

Aghebati-Maleki, L., Dolati, S., Zandi, R., Fotouhi, A., Ahmadi, M., Aghebati, A., et al. (2018). Prospect of mesenchymal stem cells in therapy of osteoporosis: a review. J. Cell. Physiol. 29, 1-9. doi: 10.1002/jcp.27833

Anderson, J. M., Rodriguez, A., and Chang, D. T. (2008). Foreign body reaction to biomaterials. Semin. Immunol. 20, 86-100. doi: 10.1016/j.smim.2007.11.004

Asatrian, G., Pham, D., Hardy, W. R., James, A. W., and Peault, B. (2015). Stem cell technology for bone regeneration: current status and potential applications. Stem Cells Cloning Adv. Appl. 8, 39-48. doi: 10.2147/SCCAA.S48423

Behera, J., and Tyagi, N. (2018). Exosomes: mediators of bone diseases, protection, and therapeutics potential. Oncoscience 5, 181-195. doi: $10.18632 /$ oncoscience.421

Bruder, S. P., Fink, D. J., and Caplan, A. I. (1994). Mesenchymal stem cells in bone development, bone repair, and skeletal regeneration therapy. J. Cell. Biochem. 56, 283-294. doi: 10.1002/jcb.240560303

Bruder, S. P., Jaiswal, N., Ricalton, N. S., Mosca, J. D., Kraus, K. H., and Kadiyala, S. (1998). Mesenchymal stem cells in osteobiology and applied bone regeneration. Clin. Orthop. Relat. Res. 335, S247-S256. doi: 10.1097/00003086-199810001-00025

Cado, G., Kerdjoudj, H., Chassepot, A., Lefort, M., Benmlih, K., Hemmerlé, J., et al. (2012). Polysaccharide films built by simultaneous or alternate spray: a rapid way to engineer biomaterial surfaces. Langmuir 28, 8470-8478. doi: $10.1021 /$ la300563s

\section{AUTHOR CONTRIBUTIONS}

$\mathrm{HR}, \mathrm{LE}, \mathrm{MD}, \mathrm{NB}, \mathrm{AM}$, and JS: participated in experiments designing and performance. HR: materials conception and cell culture. LE: qRT-PCR. MD: ELISA experiments. NB: scanning electron microscopy. JS: technical support. AM: neutrophils co-culture assay. HR, CM, SG, and HK: participated in study design and manuscript writing. All authors reviewed the results and approved the final version of the manuscript.

\section{FUNDING}

This work was partially supported by Interreg V FranceWallonie-Vlaanderen program-TEXTOS program and Geules Cassées foundation (61-2017).

\section{ACKNOWLEDGMENTS}

Authors are grateful to the staff of Reims Maternity Hospital for providing umbilical cords and to the staff of oral surgery department of Reims hospital for providing bone explants and blood samples. Authors also thank N. Bouland and C. Fichel for histology technical support, and Prof. P. Schaaf, Dr. J. Hemmerlé, and Dr. F. Boulmedais from INSERM U1121 and ICS (Strasbourg University, France) for SSCI setup.

\section{SUPPLEMENTARY MATERIAL}

The Supplementary Material for this article can be found online at: https://www.frontiersin.org/articles/10.3389/fbioe. 2019.00256/full\#supplementary-material

Chim, S. M., Tickner, J., Chow, S. T., Kuek, V., Guo, B., Zhang, G., et al. (2013). Angiogenic factors in bone local environment. Cytokine Growth Factor Rev. 24, 297-310. doi: 10.1016/j.cytogfr.2013.03.008

Crane, J. L., Xian, L., and Cao, X. (2016). Role of TGF- $\beta$ signaling in coupling bone remodeling. Methods Mol. Biol. 1344, 287-300. doi: 10.1007/978-1-4939-2966-5_18

Gao, C., Peng, S., Feng, P., and Shuai, C. (2017). Bone biomaterials and interactions with stem cells. Bone Res. 5:17059. doi: 10.1038/boneres.2017.59

Gentleman, E., Swain, R. J., Evans, N. D., Boonrungsiman, S., Jell, G., Ball, M. D., et al. (2009). Comparative materials differences revealed in engineered bone as a function of cell-specific differentiation. Nat. Mater. 8, 763-770. doi: $10.1038 /$ nmat 2505

Gerber, H. P., Vu, T. H., Ryan, A. M., Kowalski, J., Werb, Z., and Ferrara, N. (1999). VEGF couples hypertrophic cartilage remodeling, ossification and angiogenesis during endochondral bone formation. Nat. Med. 5, 623-628. doi: 10.1038/9467

Glenn, J. D., and Whartenby, K. A. (2014). Mesenchymal stem cells: Emerging mechanisms of immunomodulation and therapy. World J. Stem Cells. 6, 526-539. doi: 10.4252/wjsc.v6.i5.526

Golchin, A., and Farahany, T. Z. (2019). Biological products: cellular therapy and FDA approved products. Stem Cell Rev. 15: 166-175. doi: 10.1007/s12015-018-9866-1

Haumer, A., Bourgine, P. E., Occhetta, P., Born, G., Tasso, R., and Martin, I. (2018). Delivery of cellular factors to regulate bone healing. Adv. Drug Deliv. Rev. 129, 285-294. doi: 10.1016/j.addr.2018.01.010 
Helmy, A., Antoniades, C. A., Guilfoyle, M. R., Carpenter, K. L. H., and Hutchinson, P. J. (2012). Principal component analysis of the cytokine and chemokine response to human traumatic brain injury. PLOS ONE 7:e39677. doi: 10.1371/journal.pone.0039677

Jin, Y. Z., and Lee, J. H. (2018). Mesenchymal stem cell therapy for bone regeneration. Clin. Orthop. Surg. 10, 271-278. doi: 10.4055/cios.2018.10.3.271

Kaigler, D., Krebsbach, P. H., West, E. R., Horger, K., Huang, Y. C., and Mooney, D. J. (2005). Endothelial cell modulation of bone marrow stromal cell osteogenic potential. FASEB J. 19, 665-667. doi: 10.1096/fj.04-2529fje

Kon, T., Cho, T. J., Aizawa, T., Yamazaki, M., Nooh, N., Graves, D., et al. (2001). Expression of osteoprotegerin, receptor activator of NF$\kappa \mathrm{B}$ ligand (Osteoprotegerin Ligand) and related proinflammatory cytokines during fracture healing. J. Bone Miner. Res. 16, 1004-1014. doi: 10.1359/jbmr.2001.16.6.1004

Li, Y., Xiao, Y., and Liu, C. (2017). The horizon of materiobiology: a perspective on material-guided cell behaviors and tissue Engineering. Chem. Rev. 117, 4376-4421. doi: 10.1021/acs.chemrev.6b00654

Lin, D., Chai, Y., Ma, Y., Duan, B., Yuan, Y., and Liu, C. (2018). Rapid initiation of guided bone regeneration driven by spatiotemporal delivery of IL-8 and BMP-2 from hierarchical MBG-based scaffold. Biomaterials 17, 1-16. doi: 10.1016/j.biomaterials.2018.05.011

Luu, N. T., McGettrick, H. M., Buckley, C. D., Newsome, P. N., Rainger, G. E., Frampton, J., et al. (2013). Crosstalk between mesenchymal stem cells and endothelial cells leads to downregulation of cytokine-induced leukocyte recruitment. Stem Cells 31, 2690-2702. doi: 10.1002/stem.1511

Marsell, R., and Einhorn, T. A. (2011). The biology of fracture healing. Injury 42, 551-555. doi: 10.1016/j.injury.2011.03.031

McGettrick, H. M., Butler, L. M., Buckley, C. D., Rainger, G. E., and Nash, G. B. (2012). Tissue stroma as a regulator of leukocyte recruitment in inflammation. J. Leukoc. Biol. 91, 385-400. doi: 10.1189/jlb.0911458

Mechiche Alami, S., Gangloff, S. C., Laurent-Maquin, D., Wang, Y., and Kerdjoudj, H. (2016). Concise review: in vitro formation of bone-like nodules sheds light on the application of stem cells for bone regeneration. Stem Cells Transl. Med. 5, 1587-1593. doi: 10.5966/sctm.2015-0413

Mechiche Alami, S., Rammal, H., Boulagnon-Rombi, C., Velard, F., Lazar, F., Drevet, R., et al. (2017). Harnessing Wharton's jelly stem cell differentiation into bone-like nodule on calcium phosphate substrate without osteoinductive factors. Acta Biomater. 49, 575-589. doi: 10.1016/j.actbio.2016.11.042

Mechiche Alami, S., Velard, F., Draux, F., Siu Paredes, F., Josse, J., Lemaire, F., et al. (2014). Gene screening of Wharton's jelly derived stem cells. Biomed. Mater. Eng. 24, 53-61. doi: 10.3233/BME-140974

Mountziaris, P. M., and Mikos, A. G. (2008). Modulation of the inflammatory response for enhanced bone tissue regeneration. Tissue Eng. Part B Rev. 14, 179-186. doi: 10.1089/ten.teb.2008.0038

Najar, M., Krayem, M., Merimi, M., Burny, A., Meuleman, N., Bron, D., et al. (2018). Insights into inflammatory priming of mesenchymal stromal cells: functional biological impacts. Inflamm. Res. 67, 467-477. doi: 10.1007/s00011-018-1131-1

Place, E. S., Evans, N. D., and Stevens, M. M. (2009). Complexity in biomaterials for tissue engineering. Nat. Mater. 8, 457-470. doi: 10.1038/ nmat 2441

Raisz, L. G. (1999). Prostaglandins and bone: physiology and pathophysiology. Osteoarthritis Cartilage 7, 419-421. doi: 10.1053/joca.1998.0230
Rammal, H., Dubus, M., Aubert, L., Reffuveille, F., Laurent-Maquin, D., Terryn, C., et al. (2017a). Bioinspired nanofeatured substrates: suitable environment for bone regeneration. ACS Appl. Mater. Interfaces. 9, 12791-12801. doi: 10.1021/acsami.7b01665

Rammal, H., Harmouch, C., Maerten, C., Gaucher, C., Boulmedais, F., Schaaf, P., et al. (2017b). Upregulation of endothelial gene markers in Wharton's jelly mesenchymal stem cells cultured on polyelectrolyte multilayers. J. Biomed. Mater. Res. A. 105, 292-300. doi: 10.1002/jbm.a.35868

Saito, A., Nagaishi, K., Iba, K., Mizue, Y., Chikenji, T., Otani, M., et al. (2018). Umbilical cord extracts improve osteoporotic abnormalities of bone marrowderived mesenchymal stem cells and promote their therapeutic effects on ovariectomised rats. Sci. Rep. 8:1161. doi: 10.1038/s41598-018-19516-6

Schaefer, A., Te Riet, J., Ritz, K., Hoogenboezem, M., Anthony, E. C., Mul, F. P., et al. (2014). Actin-binding proteins differentially regulate endothelial cell stiffness, ICAM-1 function and neutrophil transmigration. J. Cell Sci. 127, 4470-4482. doi: 10.1242/jcs. 154708

Sugimoto, M. A., Sousa, L. P., Pinho, V., Perretti, M., and Teixeira, M. M. (2016). Resolution of inflammation: what controls its onset? Front. Immunol. 7:160. doi: 10.3389/fimmu.2016.00160

Tang, Y., Wu, X., Lei, W., Pang, L., Wan, C., Shi, Z., et al. (2009). TGF-beta1induced migration of bone mesenchymal stem cells couples bone resorption with formation. Nat. Med. 15, 757-765. doi: 10.1038/nm.1979

Ucuzian, A. A., and Greisler, H. P. (2007). In vitro models of angiogenesis. World J. Surg. 31, 654-663. doi: 10.1007/s00268-006-0763-4

Von Wedel-Parlow, M., Schrot, S., Lemmen, J., Treeratanapiboon, L., Wegener, J., and Galla, H. J. (2011). Neutrophils cross the BBB primarily on transcellular pathways: an in vitro study. Brain Res. 1367, 62-76. doi: 10.1016/j.brainres.2010.09.076

Wang, Y., Chen, X., Cao, W., and Shi, Y. (2014). Plasticity of mesenchymal stem cells in immunomodulation: pathological and therapeutic implications. Nat. Immunol. 15, 1009-1016. doi: 10.1038/ni.3002

Wu, M., Chen, G., and Li, Y. (2016). TGF- $\beta$ and BMP signaling in osteoblast, skeletal development, and bone formation, homeostasis and disease. Bone Res. 4:16009. doi: 10.1038/boneres.2016.9

Zhang, K., Wang, S., Zhou, C., Cheng, L., Gao, X., Xie, X., et al. (2018a). Advanced smart biomaterials and constructs for hard tissue engineering and regeneration. Bone Res. 6:31. doi: 10.1038/s41413-018-0032-9

Zhang, Y., Yang, W., Devit, A., and Van den Beucken, J. J. J. P. (2018b). Efficiency of coculture with angiogenic cells or physiological BMP-2 administration on improving osteogenic differentiation and bone formation of MSCs. J. Biomed. Mater. Res. A 9999, 1-11. doi: 10.1002/jbm.a.36581

Conflict of Interest: The authors declare that the research was conducted in the absence of any commercial or financial relationships that could be construed as a potential conflict of interest.

Copyright (c) 2019 Rammal, Entz, Dubus, Moniot, Bercu, Sergheraert, Gangloff, Mauprivez and Kerdjoudj. This is an open-access article distributed under the terms of the Creative Commons Attribution License (CC BY). The use, distribution or reproduction in other forums is permitted, provided the original author(s) and the copyright owner(s) are credited and that the original publication in this journal is cited, in accordance with accepted academic practice. No use, distribution or reproduction is permitted which does not comply with these terms. 